\title{
SMK KEARIFAN LOKAL TRI HITA KARANA
}

\author{
Putu Sudira \\ Pendidikan Teknik Elektronika - Fakultas Teknik UNY \\ putupanji@uny.ac.id
}

\begin{abstract}
Abstrak: SMK kearifan lokal Tri Hita Karana. SMK kearifan lokal Tri Hita Karana (THK) adalah sekolah kejuruan yang menerapkan karakter keharmonisan antara warga sekolah dengan sang pencipta Tuhan Yang Mahaesa, keharmonisan antar sesama warga sekolah, dan keharmonisan antara warga sekolah dengan lingkungan sarana dan prasarana sekolah secara keseluruhan. Pendidikan kejuruan di SMK berbasis kearifan lokal THK dapat mengantisipasi dampak negatif instrusi budaya global, karena THK telah menjadi "taksu" atau modal sosiokultural spiritual dan falsafah hidup masyarakat Bali. Pendidikan kejuruan berbasis kearifan lokal THK perlu dikembangkan secara sistematis untuk meningkatkan keunggulan lokal, kepentingan nasional, keadilan, dan kompetisi antarbangsa dalam peradaban dunia. Pengembangan SMK kearifan lokal THK didasarkan atas kebijakan pemerintah berupa UU nomor 20 Tahun 2003, PP 19 Tahun 2005, PerMenDiknas nomor 63 Tahun 2009, dan Perda Provinsi Bali nomor 16 Tahun 2009. Dengan menerapkan kearifan lokal THK, SMK dapat berkembang sebagai pusat pembudayaan kompetensi, menjadi basis pengembangan karakter dan kepribadian sumber daya insani (SDI) dengan ketrampilan kerja tinggi, budaya kerja dan budaya belajar yang kuat, serta budaya melayani orang secara tulus dan wajar. Pendidikan kejuruan berbasis kearifan lokal THK dapat melahirkan manusia yang memiliki kemampuan mengelola hidupnya dengan baik, benar, dan wajar.
\end{abstract}

Kata kunci:kearifan lokal, THK, SMK, harmonis

\section{VOCATIONAL HIGH SCHOOL INDIGENOUS TRI HITA KARANA}

\begin{abstract}
Vocational High School indigenous Tri Hita Karana. Vocational High School (VHS) indigenous Tri Hita Karana (THK) is a vocational school that implements character harmony between the school community with the creator God Almighty, harmony among the school community, and the harmony between the school community with the school facilities and infrastructure as a whole. VHS based on local wisdom THK can anticipate the negative impact of global cultural entrusion, because THK has become "taksu" or sociocultural-spiritual capital and philosophy of life of the Balinese people. Vocational education based on local wisdom THK should be developed systematically to promote the local excellence, national interest, justice, and the competition between nations in the world civilization. Development of VHS local wisdom THK based on the government policy in UU nomor 20 Tahun 2003, PP 19 Tahun 2005, PerMenDiknas nomor 63 Tahun 2009, and Perda Provinsi Bali nomor 16 Tahun 2009. By applying local wisdom THK, VHS can develop as a center of competence cultivation, the basis for the development of character and personality of human resource with high job skills, strong a work culture and learning culture, and a culture of serving the people sincerely and reasonable. Vocational education based on local wisdom THK, can deliver humans who have the ability to manage his life with the good, true, and fair.
\end{abstract}

Key words: local wisdom, THK, VHS, harmony 


\section{PENDAHULUAN}

Penanganan dampak intrusi budaya global terhadap budaya lokal salah satunya dapat dilakukan melalui inovasi pengembangan kualitas, perluasan akses, dan relevansi pendidikan berbasis budaya dan kearifan lokal (Zajda, 2008; Sing, 2009). Inovasi pengembangan kualitas, perluasan akses, dan relevansi pendidikan berbasis budaya, kearifan, dan keunggulan lokal diharapkan dapat meningkatkan kecintaan masyarakat terhadap budaya bangsa sebagai modal sosiokulturalspiritual dalam membangun peradaban baru pendidikan kejuruan modern berkarakter Indonesia. Sembari mengakrabi gempuran budaya global sambil memilah dan memilih, pendidikan kejuruan Indonesia harusnya mengedepankan pemeliharaan dan pengembangan identitas ke Indonesiaan yang unik. Pendidikan kejuruan Indonesia harus memiliki arah yang jelas, pegangan yang kuat, dan mengakar pada jati diri masyarakatnya (Rojewski, 2009; Pavlova, 2009). Pada akhirnya pendidikan kejuruan diharapkan dapat menjadi perangkat pembangunan berkelanjutan dalam meningkatkan daya saing tenaga kerja Indonesia karena kualitas dan keunikannya.

Sekolah Menengah Kejuruan (SMK) adalah satuan pendidikan tingkat menengah yang dikembangkan oleh pemerintah dan swasta untuk mendidik dan melatih masyarakat dalam berbagai bidang kompetensi keahlian. Tujuan pokok pendidikan kejuruan di SMK adalah untuk menyiapkan lulusannya bekerja, berwirausaha, atau melanjutkan ke perguruan tinggi. Untuk mewujudkan tujuan tersebut SMK dituntut mampu menginternalisasikan keseluruhan konteks pendidikan kejuruan ke dalam input dan proses, sehingga output dan outcome sistem pendidikan SMK optimal (Slamet, 2008). Sekolah Menengah Kejuruan (SMK) Tri Hita Karana adalah SMK berbasis kearifan lokal yang mengajarkan nilai-nilai keharmonisan warga sekolah yang dilandasi oleh keharmonisan antara warga sekolah dengan sang pencipta Tuhan Yang Mahaesa, keharmonisan antar sesama warga sekolah, dan keharmonisan antara warga sekolah dengan lingkungan sarana dan prasarana sekolah secara keseluruhan. SMK THK adalah lembaga pendidikan kejuruan formal pada tingkat menengah yang bertujuan menghasilkan lulusan untuk bekerja, berwirausaha, dan melanjutkan ke perguruan tinggi sesuai bidang studi keahliannya dimana nilai-nilai luhur THK dijadikan sebagai bagian dari pengembangan standar kompetensi lulusan, standar isi program, standar proses pembelajaran, standar pendidik dan tenaga kependidikan, standar saranaprasarana, standar pengelolaan, standar biaya, dan standar penilaian.

Selain perkembangan teknologi khususnya Teknologi Informasi dan Komunikasi (TIK), industri berbasis pengetahuan, industri kreatif, regulasi pemerintah, tuntutan kompetensi dan ketrampilan kerja, dan perkembangan pendidikan tinggi, SMK harus memperhatikan kearifan lokal (indigenous wisdom) masyarakat setempat. Kearifan lokal bagi masyarakat Bali merupakan "taksu" atau modal dasar untuk mengembangkan sumber daya insani (SDI). Kearifan lokal dapat 
digunakan oleh SMK dalam membina dan mengembangkan pendidikan kejuruan. Dengan menerapkan kearifan lokal, SMK dapat berkembang sebagai pusat pembudayaan kompetensi, menjadi basis pengembangan karakter dan kepribadian SDI dengan ketrampilan kerja tinggi dan memiliki keunikan dalam tata nilai khususnya tata nilai kejuruan.

Disamping memperhatikan konteks perkembangan global, inovasi pengembangan pendidikan kejuruan juga sangat perlu memperhatikan konteks lokal berupa kebutuhankebutuhan nasional, keunggulan lokal, dan kearifan-kearifan lokal masing-masing daerah (Oketch, 2009; Coessens, 2008; Chinien, Boutin, Plane, 2009). Sasarannya adalah agar pendidikan kejuruan dapat berkembang secara seimbang dan berkelanjutan untuk keharmonisan dan kemajuan sosial bersama, memberi kontribusi pada keharmonisan dan pelestarian lingkungan, pelestarian nilai-nilai budaya, pengukuhan identitas bangsa, bijak dalam menggunakan sumber daya alam, efektif, efisien dalam melakukan perbaikan tenaga kerja terdidik dan terlatih (Chinien and Singh, 2009). Bagaimana pendidikan kejuruan berhasil melakukan vokasionalisasi dalam memodali masyarakat pekerja dan pencari kerja dengan pengetahuan, nilai-nilai lokal, sikap, prilaku, dan ketrampilan yang dibutuhkan agar dapat berpartisipasi penuh dalam masyarakat secara efektif. Bagaimana vokasionalisasi sebagai proses penimbaan ilmu (acquisition of knowledge), pencernaan ilmu (digestion of knowledge), pembuktian ilmu (validation of kowledge), dan pengembangan ketrampilan dapat berjalan diantara masyarakat pekerja dan pencari kerja. Bersama-sama dengan dunia usaha dan dunia industri proses vokasionalisasi berjalan menerapkan pembelajaran berbasis kerja dan menciptakan lingkungan belajar yang mendidik.

Permasalahan pokok yang dihadapi SMK dalam menginternalisasikan konteks kearifan lokal sebagai modal dasar pengembangan sekolah kejuruan antara lain: (1) apakah ada kebijakan pemerintah pusat dan daerah tentang pendidikan berbasis kearifan lokal; (2) apakah terjadi keselarahan konsep kearifan lokal dengan tuntutan pembangunan pendidikan kejuruan; (3) apakah nilai-nilai kearifan lokal selaras dengan visi dan misi pendidikan kejuruan; bagaimana pemahaman dan penghayatan terhadap nilai-nilai kearifan lokal; dan (5) bagaimana komitmen pengelola pendidikan kejuruan di daerah dalam menerapkan kearifan lokal.

\section{PEMBAHASAN}

\section{Kebijakan Pendidikan Kejuruan Berbasis Kearifan Lokal}

Pelaksanaan program pendidikan kejuruan di SMK berbasis kearifan lokal THK membutuhkan dukungan kebijakan dalam bentuk peraturan perundang-undangan. Karena tanpa peraturan perundang-undangan yang jelas program pendidikan kejuruan berbasis keunggulan lokal tidak bisa dilaksanakan dan tidak bisa didanai oleh pemerintah. Kebijakan pokok tentang pendidikan berbasis keunggulan lokal diatur dalam undang-undang Sisdiknas Nomor 20 Tahun 2003 Pasal 50 ayat 5 yang 
menyatakan bahwa pemerintah kabupaten/kota mengelola pendidikan dasar dan pendidikan menengah, serta satuan pendidikan yang berbasis keunggulan lokal. Kebijakan ini menegaskan pula bahwa pemerintah daerah Bali perlu mengembangkan dan membangun pendidikan kejuruan berbasis keunggulan lokal THK secara berencana dan berkala untuk meningkatkan keunggulan lokal, kepentingan nasional, keadilan, dan kompetisi antarbangsa dalam peradaban dunia. Kemudian dalam PP 19 Tahun 2005 tentang standar nasional pendidikan dinyatakan kurikulum SMK dapat memasukkan pendidikan berbasis keunggulan lokal. Pendidikan berbasis keunggulan lokal merupakan bagian dari pendidikan kelompok mata pelajaran agama dan akhlak mulia, pendidikan kelompok mata pelajaran kewarganegaraan dan kepribadian, pendidikan kelompok mata pelajaran ilmu pengetahuan dan teknologi, pendidikan kelompok mata pelajaran estetika, atau kelompok mata pelajaran pendidikan jasmani, olah raga, dan kesehatan. Pendidikan berbasis keunggulan lokal merupakan bagian dari kurikulum SMK.

Penjaminan mutu pendidikan kejuruan berbasis keunggulan lokal diatur dalam Peraturan Menteri Pendidikan Nasional nomor 63 Tahun 2009. SMK yang dapat menggunakan program pendidikan berbasis keunggulan lokal adalah SMK yang telah melampaui standar pelayanan minimal (SPM) dan standar nasional pendidikan (SNP). Standar mutu di atas SNP yang berbasis keunggulan lokal dapat dirintis pemenuhannya oleh satuan pendidikan yang telah memenuhi SPM dan sedang dalam proses memenuhi SNP. Pendidikan berbasis keunggulan lokal dapat diperoleh peserta didik dari satuan pendidikan yang bersangkutan atau dari satuan pendidikan nonformal yang sudah memperoleh akreditasi.

Dukungan kebijakan pengembangan SMK kearifan lokal THK secara tersirat juga tertuang dalam bentuk peraturan daerah Provinsi Bali nomor 16 Tahun 2009 tentang Rencana Tata Ruang Wilayah Provinsi Bali menyatakan bahwa Tri Hita Karana adalah falsafah hidup masyarakat Bali yang memuat tiga unsur yang membangun keseimbangan dan keharmonisan hubungan antara manusia dengan Tuhan, manusia dengan manusia, dan manusia dengan lingkungannya yang menjadi sumber kesejahteraan, kedamaian, dan kebahagiaan bagi kehidupan manusia. Pasal 3 menyatakan penataan ruang wilayah provinsi bertujuan untuk mewujudkan: a) ruang wilayah provinsi yang berkualitas, aman, nyaman, produktif, berjatidiri, berbudaya Bali, dan berwawasan lingkungan berlandaskan Tri Hita Karana; b) pengembangan kegiatan perekonomian pedesaan berbasis pertanian, kerajinan, industri kecil, dan pariwisata kerakyatan yang berlandaskan falsafah Tri Hita Karana yang ditunjang dengan pemenuhan sarana dan prasarana untuk menekan urbanisasi. Pengembangan kawasan perkotaan berdasarkan falsafah Tri Hita Karana, disesuaikan dengan karakter sosial budaya masyarakat setempat, dengan orientasi ruang mengacu pada konsep catus patha dan tri mandala serta penerapan gaya arsitektur tradisional Bali. 
Tujuan penataan ruang wilayah Provinsi Bali dan tujuan pengembangan perekonomian pedesaan berbasis pertanian, kerajinan, industri kecil, dan pariwisata kerakyatan dalam Perda Provinsi Bali nomor 16 Tahun 2009 bila dikaitkan dengan pembinaan dan pengembangan pendidikan kejuruan di SMK berbasis THK sangat tepat sebagai kearifan lokal. Pengembangan SMK kearifan lokal THK membutuhkan keharmonisan dan keseimbangan unsur manusia warga SMK dalam pengembangan budaya belajar, budaya melayani, dan budaya kerja berdasarkan falsafah THK dalam membangun kesejahteraan, kedamaian, dan kebahagiaan bersama. SMK sebagai lembaga pendidikan kejuruan yang mendukung pengembangan kegiatan perekonomian berbasis pertanian, kerajinan, industri kecil, dan pariwisata dibangun dan ditata menggunakan konsep catus patha dan tri mandala untuk mewujudkan tata ruang wilayah sekolah yang berkualitas, nyaman, aman, produktif, dan berwawasan lingkungan.

\section{Konsep Kearifan Lokal THK dalam Pendidikan Kejuruan di SMK}

Konsep THK merupakan integrasi sistemik dari konsep “сисири manik" atau konsep "isi dan wadah" (Agastia, 2007). Pertalian yang harmonis seimbang antara isi dan wadahnya adalah syarat terwujudnya kebahagiaan manusia (jana hita) dan kebahagiaan dunia (jagat hita) (Wiana, 2009). Konsep сисири manik menegaskan bahwa akan selalu terjadi dinamika, perubahan isi membutuhkan perubahan wadah sebaliknya perubahan wadah membutuhkan perubahan isi.
Sebagai contoh perubahan IPTEKS, ICT, globalisasi sebagai perubahan wadah membutuhkan perubahan sikap dan kompetensi pada diri manusia.

Kebudayaan Bali menyatakan manusia adalah bhuwana alit sebagai isi (manik) sedangkan alam semesta ini bhuwana agung sebagai wadahnya (сисири). Membangun kehidupan bahagia, seimbang dan harmonis dalam perspektif pengembangan pendidikan kejuruan di SMK berbasis THK ditemukan konsep-konsep sebagai dijabarkan dibawah ini. Harmonis artinya melakukan hal-hal baik dan memiliki kesucian terepleksi mulai dari pikiran (idep), terucap dalam perkataan (sabda) dan terlihat dalam tindakan perbuatan (bayu).

Pertama: manusia sebagai manik merupakan mahluk berpikir dan berbudaya memiliki kekuatan atau prana (sabda, bayu, idep) untuk mengembangkan wadah bagi dirinya. Manusia membuat rumah, banjar, desa pekraman, sekolah (SMK), hotel, pabrik, kantor dan sebagainya selaku wadah bersama baginya. Harapannya adalah agar wadah buatannya ini memberikan rasa bahagia serta mempunyai pertalian serasi dengan manusia pendidikan kejuruan selaku isinya. Maka demi kebahagiaan ini dikonsepsikanlah rumah, desa pakraman, sekolah (SMK), hotel, pabrik, kantor dan sebagainya sebagai wadah buatan.

Kedua: THK memiliki unsur jiwa, prana, dan sarira yang dalam wadah buatan direalisasikan dalam tiga "Pa" yaitu: parhyangan, pawongan, dan palemahan. Ketiga unsur tersebut adalah sesuatu yang integral sistemik, memiliki keterkaitan satu sama lain 
dalam sebuah kemanunggalan untuk mencapai kebahagiaan. Dalam diri manusia jiwa/atman adalah unsur parhyangan, prana (sabda, bayu, idep) adalah unsur pawongan, dan badan/tubuh berfungsi sebagai palemahan. Konsep THK membangun kesadaran bahwa setiap manusia memiliki tiga modal dasar untuk hidup bahagia yaitu : (1) atman/jiwa; (2) prana/kekuatan sabda-bayu-idep; dan (3) angga sarira/ badan wadag. Hilang atau melemahnya salah satu unsur THK dalam diri manusia maka kebahagiaan itu akan hilang juga. Angga sarira/badan tanpa atman/jiwa adalah jenazah, atman/jiwa tanpa angga sarira/badan adalah hantu, atman/jiwa dengan angga sarira/badan tanpa prana atau kekuatan sabda-bayu-idep sama dengan manusia sakit tanpa potensi. Dalam ranah pengembangan kompetensi pendidikan kejuruan konsep ini menjadi modal moral dan mental.

Ketiga: dalam wadah rumah tangga atau keluarga sanggah/pemerajan adalah parhyangan yang berfungsi sebagai jiwanya keluarga, sedangkan anggota keluarga adalah pawongan sebagai kekuatan/prana rumah tangga, dan karang atau areal rumah adalah palemahan. Sanggah/pemerajan sebagai parhyangan adalah jiwa pemberi kehidupan bagi semua anggota keluarga. Kebahagiaan di dalam rumah tangga adalah perwujudan harmonisasi antar anggota keluarga (ibu, bapak, anak), harmonisasi antara anggota keluarga dengan sanggah/pemerajan, dan harmonisasi antara anggota keluarga dengan lingkungan dan bangunan rumah.
Keempat: dalam wadah desa pakraman, kahyangan tiga yaitu Pura Desa sebagai tempat pemujaan Bhatara Brahma, Pura Puseh sebagai tempat pemujaan Bhatara Wisnu, dan Pura Dalem sebagai tempat pemujaan Bhatara Siwa adalah parhyangan yang merupakan jiwanya dari warga desa pekraman (Wiana, 2008). Segenap warga desa pakraman adalah pawongan dan batas-batas wilayah desa pakraman dengan keseluruhan bangunan dan alam yang tumbuh adalah palemahan. Pemujaan kahyangan tiga dilandasi penguatan ajaran Tri Kona dan Tri Guna mengarahkan warga desa pakraman untuk selalu kreatif mengembangkan gagasan-gagasan, melakukan program aksi yang bermanfaat bagi kebahagiaan warga desa pakraman (jana hita-jagat hita), membangun alam lestari (butha hita) (Wiana, 2009). Desa pakraman memberikan penguatan identitas jati diri masyarakat Bali yang memiliki akar budaya yang kuat dan terbuka terhadap masukan dan pengaruh global (teori Pohon).

Kelima: dalam wadah sekolah SMK, Pura Sekolah adalah parhyangan sebagai jiwanya warga SMK (Kepala Sekolah, Komite Sekolah, Guru, pegawai tata usaha, teknisi, laboran, siswa, satpam, tukang kebun, tukang parkir, penjaga kantin). Kepala sekolah, komite sekolah, guru, pegawai tata usaha, teknisi, laboran, siswa, satpam, tukang kebun, tukang parkir, penjaga kantin adalah pawongan sebagai prana atau tenaga penggerak sekolah (SMK). Kemajuan SMK akan sangat ditentukan oleh keadaan atau kondisi pawongannya. Kondisi masing-masing unsur pawongan SMK yang sehat jasmaninya, tenang rohaninya, dan 
profesional dalam melaksanakan tugas dan kewajibannya (swadharma) akan sangat mendukung kesuksesan SMK menjalankan visivisi meraih tujuan. Lingkungan sekolah lengkap dengan bangunan gedung sarana dan prasarana PBM, pasilitas TIK, bahan ajar, bahan belajar,sumber-sumber belajar, bahan praktikum adalah unsur palemahan yang terus harus dibangun.

\section{Nilai-Nilai Kearifan Lokal THK dalam Pendidikan Kejuruan di SMK}

Tri Hita Karana itu adalah hukum Tuhan, hukum alam, dan hukum kebersamaan. Memuja Tuhan (parhyangan) harus dalam kerangka menguatkan kesadaran pemeliharaan alam (palemahan) dan mengembangkan kebersamaan (pawongan) (Titib, 2007; Waskita, 2005). Parhyangan yang dibangun di desa pakraman, di rumah, di SMK dimaksudkan untuk menguatkan diri siswa, pendidik, tenaga kependidikan, masyarakat dalam mengembangkan profesi, memelihara lingkungan, dan membangun kebersamaan diantara sesama warga.

Parhyangan difungsikan untuk mengembangkan diri manusia itu sendiri sebagai bagian dari orang lain sehingga siap melayani sesama bukan untuk kepentingan diri yang eksklusif. Ilmu itu bukan untuk eksklusif tetapi untuk integratif. Inilah yang dipakai bekal dan modal oleh orang yang memiliki ilmu atau memiliki kompetensi untuk melayani orang lain (Wiana, 2008). Melayani orang lain tanpa bekal kompetensi adalah niscaya. Sehingga parhyangan yang dibangun di SMK itu adalah untuk menghilangkan ego manusia, yakni perubahan dari wiswawara (eksklusif) menjadi wiswamitra (integratif) (Wiana, 2009). Akibatnya akan selalu ada sikap mental melayani dan bukan dilayani.

Tidak ada yang bisa dilakukan dengan sempurna tanpa kekuatan moral dan keteguhan mental. Dalam THK moral dan mental akan kuat apabila alam dan lingkungannya baik. Maka pertama-tama harus pelestarian alam (bhuta hita) terlebih dahulu (Wiana, 2009). Pendidikan membutuhkan lingkungan terkondisi. Untuk memajukan pendidikan kejuruan di Bali harus ada wawasan dan pandangan budaya yang kuat sehingga seberapa pun majunya pergerakan masyarakat Bali tidak kehilangan akar kepribadiannya. Pendidikan harus melahirkan manusia yang memiliki kemampuan mengelola hidupnya dengan baik dan benar. Tanpa membangun karakter yang luhur pendidikan itu akan menimbulkan dosa sosial. Kalau sekolah menyelenggarakan pendidikan untuk mengajar peserta didik hanya untuk mencari nafkah, maka pendidikan itu tidak akan membawa perbaikan hidup dalam masyarakat. Menyadari hal ini pendidikan harus diselenggarakan dengan nilai tambah moralitas THK dan kebudayaan Bali.

\section{Pemahaman dan Penghayatan Nilai-Nilai Kearifan Lokal THK di SMK}

Penjabaran hakekat dan visi kerja bagi masyarakat Bali terkait dengan pendidikan untuk dunia kerja dan kecakapan hidup (life skill) bentuknya ada di desa pakraman dan banjar. Dalam desa pakraman ada desa dresta atau kebiasaan-kebiasaan atau tradisi adat istiadat yang diyakini dan dijalankan. Desa pakraman adalah organisasi setingkat desa yang 
memiliki anggota atau warga desa sebagai pawongan, batas-batas wilayah sebagai palemahan, kahyangan tiga sebagai parhyangan. Desa pakraman pada hakikatnya adalah sebagai lembaga sosial religius Hinduistis (Waskita, 2007). Dalam setiap desa pakraman terdapat kahyangan tiga yaitu Pura Desa, Pura Puseh, dan Pura Dalem. Ketiga pura ini mewadahi pemujaan kepada Brahma di Pura Desa sebagai pencipta (utpati), Wisnu sebagai pemelihara (stiti) di Pura Puseh, dan Siwa di Pura Dalem sebagai pelebur (pralina). Brahma, Wisnu, Siwa disebut Tri Murti dan fungsinya yaitu utpati, stiti, pralina disebut Tri Kona. Lalu apa kaitannya dengan pendidikan dunia kerja?

Tri Kona (utpati, stiti, pralina) mewadahi konsep inovasi, kreativitas, budaya preservatif, dan budaya progresif. Terbuka terhadap pengaruh global tetapi tetap mengakar pada budaya dan identitas diri sendiri (teori pohon). Inovasi, kreativitas, dan perubahan memungkinkan pada dua sisi berlawanan yaitu membangun atau merusak. Agar perubahan itu memberi nilai positif dan membangun, desa pakraman mengenal ajaran Tri Guna (sattwam, rajas, tamas). Tri Guna yang terkendali akan memberikan perubahan itu kearah positif. Akan terjadi proses penciptaan (utpati) apa-apa yang dibutuhkan, akan terjadi proses pemeliharaan (stiti) hal-hal yang masih relevan, berguna, memberi manfaat dan peleburan (pralina) halhal yang sudah tidak relevan. Kalau manusia itu dikuasai oleh Tri Guna yang tepat dia akan ciptakan hal-hal yang beguna, bukan sekedar mencipta dan memelihara hal-hal yang edonis. Pemujaan Brahma, Wisnu, dan Siwa mengamalkan dua hal yaitu Tri Kona dan Tri Guna.

Ciri hidup yang baik dan benar itu adalah melakukan kreativitas untuk menciptakan sesuatu yang sepatutnya diciptakan (utpati). Selanjutnya kreatif untuk memelihara sesuatu yang sepatutnya dipelihara (stiti). Dalam kehidupan ini ada hal-hal yang memang seyogianya ditiadakan (pralina) agar dinamika hidup ini melaju menuju kehidupan yang jana hita dan jagat hita (Wiana, 2009). Jana hita artinya kebahagiaan secara individu dan jagat hita adalah kebahagiaan secara bersama-sama. Inilah yang seyogianya yang dikembangkan oleh warga di desa pakraman.

Untuk mencapai kehidupan yang sukses hendaknya tiga sifat yang disebut Tri Guna itu harus dibuat menjadi kuat. Tri Guna itu akan kuat apabila guna sattwam dan guna rajas samasama kuat mempengaruhi citta atau alam pikiran (Wiana, 2008). Guna sattwam dan rajas yang sama-sama kuat itu menyebabkan orang selalu berniat baik dan berbuat baik. Karena itu, dibangunnya Pura Desa dan Pura Puseh dalam satu areal atau satu palemahan sebagai simbol untuk menyatukan guna sattwam dan guna rajas agar sama-sama kuat mempengaruhi citta atau alam pikiran manusia berniat baik berbuat baik. Guna sattwam dan guna rajas mengembangkan berbagai gagasan dan program untuk mendinamiskan upaya kreativitas dan perlindungan pada hal-hal yang positif (Wiana, 2009).

Lewat Pura Puseh umat dimotivasi untuk membangun niat baik dengan menguatkan sifatsifat sattwam dan berbuat baik membangun 
program-program aksi yang praktis dan realistis yang bermanfaat bagi krama di desa pakraman. Dari Pura Desa dan Pura Puseh itulah dikembangkan gagasan-gagasan untuk menentukan berbagai langkah, apa yang wajib dipelihara dan dilindungi. Sesungguhnya ada warisan budaya berupa gagasan-gagasan atau ide-ide mulia yang terpendam dalam berbagai tradisi yang patut dipelihara dan dilindungi. Warisan budaya berupa pemikiran itu bisa terekam dalam bentuk tertulis, lisan atau dalam wujud simbol-simbol visual.

Lewat pemujaan Batara Wisnu kita kuatkan moral dan daya tahan mental kita untuk melindungi hal-hal yang patut dilindungi dari arus zaman yang sangat deras. Untuk melindungi sesuatu yang patut dilindungi itulah sebagai wujud nyata aktivitas memuja Batara Wisnu di Pura Puseh. Untuk bisa membedakan antara yang patut dilindungi dan yang tidak patut dilindungi itu perlu dibangun wiweka jnana. Wiweka jnana adalah suatu kemampuan untuk membeda-bedakan yang patut dan yang tidak patut, yang baik dan yang tidak baik dan seterusnya. Hal itu penting agar jangan semua yang sudah mentradisi terus kita lindungi. Lagi pula tradisi itu adalah buatan manusia. Setiap buatan manusia itu pasti kena hukum rwa bhineda. Ada yang baik ada yang buruk. Dengan wiweka jnana kita akan melindungi sesuatu yang patut dilindungi, memelihara sesuatu yang patut dipelihara.

Selanjutnya ada penjelasan dalam bahasa Jawa Kuno didalam Wrehaspati Tattwa dinyatakan "sakti ngarania ikang sarwa jnyana lawan sarwa karya" (Wiana, 2009). Artinya: sakti adalah mereka yang memiliki banyak ilmu (jnana) dan banyak berbuat nyata mewujudkan ilmu tersebut. Konsep sakti memunculkan konsep cendikiawan yaitu kemampuan berbuat memecahkan permasalahan yang ada di masyarakat melalui disiplin ilmu yang dimiliki. Untuk memiliki banyak ilmu haruslah mengembangkan guna sattwam. Mereka yang guna sattwam-nya kuat akan terdorong untuk terus meningkatkan kemauan belajarnya dan memiliki kecerdasan belajar (learning intellegence) sebagai pusat pengembangan diri manusia abad 21. Sedangkan mereka yang memiliki guna rajas yang kuat akan selalu memiliki semangat kuat untuk terus bekerja mewujudkan ilmu yang didapatkan dalam perbuatan nyata. Demikian juga keberadaan Pura Dalem untuk memuja Tuhan sebagai Dewa Siwa Rudra. Pemujaan Tuhan di Pura Dalem diarahkan untuk menguatkan kemampuan untuk mengendalikan sifat-sifat tamas agar tidak eksis membuat manusia malas, bebal tetapi rakus. Dalam wujud yang lebih nyata pembinaan guna tamas akan mendorong manusia melakukan langkah-langkah nyata menghilangkan berbagai ancaman, gangguan, hambatan dan tantangan hidup.

Swadharma desa pakraman yang dijiwai oleh keberadaan Kahyangan Tiga ini adalah mengembangkan ajaran Tri Kona dan Tri Guna dalam membangun warga desa pakraman (pawongan) yang jagat hita (bahagia di dunia). Pemujaan pada Tuhan di Kahyangan Tiga (parhyangan) akan bermakna untuk membangun alam yang lestari (bhuta hita) dan manusia Bali yang jagat hita. Membangun alam yang lestari 
dengan konsep Rta. Sedangkan membangun jagat hita dengan konsep dharma. Ini artinya memuja Tuhan bukan berhenti pada memuja saja. Pemujaan Tuhan harus dapat berdaya guna menguatkan manusia untuk menjaga alam dan menjaga hidup bersama yang saling mengabdi. Itulah tujuan pendirian Kahyangan Tiga di desa pakraman (Wiana,2009).

Kearifan lokal masyarakat Bali terkait dengan jana hita dan jagat hita untuk pendidikan untuk dunia kerja adalah "ngalih gae pang meturu idup" bukan "mati iba idup kai" (Wiana, 2009). Bagaimana masyarakat Bali mencari pekerjaan, membangun pekerjaan untuk hidup dan menghidupi kebutuhan bersama. Bukan mengembangkan cara-cara untuk membunuh kehidupan orang lain, menindas kehidupan orang untuk hidup bahagia diatas penderitaan orang lain. Bukan sekedar menyelamatkan diri masing-masing.

Dinamika hidup dengan landansan Tri Kona inilah yang dapat menciptakan suasana hidup yang dinamis, harmonis dan produktif dalam arti spiritual dan material secara berkesinambungan. Dari konsep Tri Kona ini sesungguhnya dapat dikembangkan menjadi berbagai kebijakan di desa pakraman. Betapapun maju suatu zaman yakinlah dapat dikendalikan dengan konsep Tri Kona (Wiana, 2009). Dengan konsep Tri Kona ini desa pakraman tidak akan pernah kehilangan jati dirinya sebagai lembaga umat Hindu khas Bali. Kemajuan zaman justru akan menguatkan jati diri kehidupan di desa pakraman. Ciptakan adatistiadat yang dibutuhkan zaman, ada adatistiadat yang masih baik dan benar agar terus dipelihara dan dipertahankan. Sedangkan adatistiadat yang sudah usang ketinggalan zaman hendaknya ditinggalkan secara suka rela dengan cara-cara yang baik dan benar juga. Dewasa ini, karena kurang kuatnya guna sattwam dan guna rajas, banyak tindakan melidungi sesuatu yang sudah sepatutnya dipralina, dan mengabaikan sesuatu yang sepatutnya mendapatkan pemeliharaan dan perlindungan.

Di desa pakraman, Pesraman, dan Banjar juga sebagai tempat dan lembaga membuat orang agar mengerti dalam menggerakkan hidupnya secara vertikal dan horizontal. Vertikal itu Catur Asrama yaitu: brahmacari, grihasta, wanaprasta, dan bhiksuka. Brahmacari adalah masa menuntut ilmu, grihasta masa berumah tangga, Wanaprasta masa menjauhi kehidupan duniawi, dan Bhiksuka masa menyerahkan diri kepada Tuhan. Secara horizontal Catur Warna (brahmana, ksatria, waisya, sudra). Makanya di Banjar, betara dipuja sebagai Betara Penyarikan agar masyarakat "nyarik-nyarik". "brahmacari pang seken; grihasta pang seken; wanaprasta pang seken; bhiksuka pang seken" (Wiana, 2010). Memiliki keahlian dan keterampilan serta siap memasuki pilihan warna dan asrama. Gerak masyarakat melalui jalur horizontal dengan Catur warna dan secara vertikal menjalani pengasraman (Catur Asrama). Keluhuran kearifan lokal Bali: brahmana adalah memelihara dan mengembangkan ilmu; kesatria perlindungan; waisya kemakmuran; sudra tenaga kerja. Brahmana berkerja membangun kekuatan moral, kesejukan hati. Kesatria membangun kekuatan regulasi, memberi 
keamanan, dan keadilan. Waisya bekerja membangun kekuatan ekonomi dan memberi kesejahteraan. Sudra membangun kekuatan demokrasi memberi kerukunan me-nyame braya, kekeluargaan dan kebersamaan dalam hidup berdampingan (Sutantra, 2010).

Dalam lingkup keluarga THK dilembagakan dalam bentuk rumah adat keluarga Bali. Sama halnya dengan desa pakraman, penataan rumah adat menggunakan konsep tri mandala dan tri angga. Sanggah sebagai parhyangan adalah otak, meten merupakan kepala pembungkus otak, bale dauhbale dangin sebagai tangan kiri-kanan, dapur adalah perut, dan tebe adalah kaki. Bangunan pokok dalam sanggah adalah kemulan, taksu, dan padmasana. Kemulan adalah modal untuk membangun rumah tangga, taksu adalah kekuatan. Kalau tidak ada kekuatan taksu maka modal atau kemulan kita bisa tidak tumbuh berkembang. Padmasana digunakan untuk memuja Tuhan Ida Sang Hyang Widhi (Widia Dharma, 2010).

\section{Komitmen Pengelola Pendidikan di SMK THK}

Pendidikan kejuruan di SMK sebagai pendidikan untuk pengembangan kompetensi kerja SDI akan berhasil baik jika mampu menumbuhkembangkan eksistensi manusia pendidikan kejuruan yang memasyarakat, berbudaya kompetensi dalam tatanan kehidupan berdimensi lokal, nasional, regional, dan global (Cheng, 2005; Clarke \& Winch, 2007; Pavlova, 2009). Sebagai produk masyarakat, pendidikan kejuruan tidak bisa dipisahkan dari masyarakat dimana pendidikan kejuruan dikembangkan.
Pendidikan kejuruan tumbuh dari masyarakat, berkembang bersama budaya dan tradisi masyarakat setempat, memperhatikan kearifan lokal, keunggulan lokal, potensi wilayah, dukungan masyarakat, partisipasi dan kerjasama masyarakat, ada konsensus yang kuat diantara masyarakat dengan lembaga pendidikan kejuruan (Thompson, 1973; Wagner, 2008, Hampden, Thompson, Guzman, and Lippman, 2008). Visi pendidikan kejuruan seharusnya kongruen dengan visi masyarakat dimana pendidikan kejuruan dikembangkan (Tilaar, 1999).

Bali memiliki konsep-konsep yang khas untuk kelangsungan hidupnya. Konsep tersebut menyangkut kehidupan fisik (sekala) maupun non fisik (niskala), menyangkut tata ruang dan kebijakan pemanfaatan lahan pertanahan, menyangkut tata kemasyarakatan dalam wadah lembaga-lembaga sosial kemasyarakatan desa pakraman. Bali dalam perspektif ideologi Tri Hita Karana (THK) adalah sebuah kesatuan yang utuh, sehingga segala program dan kebijakan yang menyangkut Bali harus dilakukan secara sinergis, integral, dan sistemik. Bali tumbuh dengan alam dan kebudayaannya dalam menentukan masa depannya. Oleh karena itu, pengelolaan dan pengembangan alam dan kebudayaan Bali harus tetap berdasarkan ideologi THK (Agastia, 2007). Demikian juga dengan pengembangan dan pengelolaan pendidikan kejuruannya.

Praksis ideologi THK dapat digunakan sebagai solusi dari permasalahan-permasalahan pengembangan SDM Bali pada umumnya dan khususnya dalam inovasi dan pengembangan 
kualitas pendidikan kejuruan di era ekonomi berbasis pengetahuan. Praksis ideologi THK adalah kemungkinan atas jawaban permasalahan-permasalahan menurunnya daya saing bangsa, melemahnya integritas dan identitas nasional. Keberlangsungan (sustainability) mutu dan relevansi pendidikan kejuruan di Bali sangat ditentukan oleh kemampuan lembaga SMK dalam menerapkan kearifan lokal Bali secara terencana dan terprogram dengan tetap menyerap standar nasional dan internasional. Salah satu indigenous wisdom masyarakat Bali yang telah diakui oleh UNESCO adalah Tri Hita Karana (THK).

THK adalah ideologi yang mengajarkan keharmonisan dan keseimbangan hidup dalam mewujudkan tujuan hidup moksartham jagat hita ya ca iti dgharma (kebahagiaan duniawi/jagadhita dan kebahagiaan rokhani. Tri Hita Karana adalah tiga unsur penyebab atau sebab musabab terjadinya kebahagiaan hidup pada diri manusia. Ketiga unsur sebab musabab itu adalah: (1) zat Hyang Widhi atau Atman; (2) prana dalam bentuk sabda, bayu, idep sebagai daya yang timbul karena menyatunya Atman dengan badan wadag; dan (3) sarira atau badan wadag manusia yang terbentuk dari lima unsur yang disebut dengan panca mahabhuta (ruang/akasa, teja/panas, udara/bayu, zat cair/apah, zat padat/pertiwi). Kebahagiaan akan terwujud jika ada keharmonisan antara Atman dengan badan wadag sebagai wadahnya. Keharmonisan antara Atman dengan badan wadag akan membangkitkan prana yang berkualitas tinggi. Konsep ini kemudian dikenal dengan konsep keharmonisan "сисири lan Manik" yaitu keharmonisan antara wadah/cuсири dan isi/manik. Ideologi THK dan konsep сисири lan manik sangat baik dan bahkan ideal digunakan sebagai basis pengembangan pendidikan karena pendidikan pada dasarnya adalah proses menumbuhkan modal THK yang ada pada diri manusia itu sendiri.

Pada kenyataannya pendidikan kita di Bali secara terstruktur belum menggunakan THK sebagai basis tata nilai pengembangan mutu dan relevansi. Beberapa lembaga pendidikan telah menyebut THK sebagai landasan pengembangan pendidikan dalam visi dan misi sekolahnya, telah menggunakan sebagai basis pengembangan satu mata pelajaran, akan tetapi belum jelas tujuan, sasaran pokok, dan strategi yang digunakan untuk mengimplementasikan nilai-nilai luhur THK. Salah satu penyebab terjadi permasalahan tersebut adalah belum banyak penelitian dan pengkajian yang mendalam tentang konsep pengembangan sekolah model indigenous wisdom THK. Konsep ini harus memberi arah yang jelas tentang nilai-nilai inti dan luhur (core values) yang dipilih dan akan dibangun melalui pendidikan di SMK. SMK indigenous wisdom THK harus melibatkan semua stakeholder dalam komunitas sekolah, mengimplementasikan core values THK kedalam kurikulum sekolah. Agar memberi hasil yang maksimal komunitas sekolah yaitu guru, siswa, tenaga kependidikan, tenaga administrasi, penjaga sekolah, tukan kebun harus mampu mempromosikan core ethical dan performance 
values THK yang telah ditetapkan sebagai fondasi pembentukan karakter peserta didik. Ini harus diawali dengan adanya guru model THK, bangunan THK, simbol-simbol nilai THK dalam bangunan sekolah, peralatan siswa. Guru, siswa, tenaga kependidikan, keluarga, komite sekolah memahami bagaimana dan mengapa sekolah memilih nilai pokok dan mengafirmasi pentingnya nilai pokok dalam menuntun perilaku. Etika luhur dan nilai-nilai secara aktif digunakan sebagai panduan dalam setiap aspek kehidupan di sekolah. Guru, siswa, staff, keluarga menggunakan bahasa yang sama sebagai refleksi nilai luhur sekolah THK. Ada guru model yang dapat mengintegrasikan nilainilai ke dalam kehidupan sekolah. Nilai luhur memandu praktek-praktek pengajaran dan pembelajaran siswa secara terprogram baik dalam program kurikuler maupun ekstra kurikuler.

Perkembangan pariwisata dan jaringan internasional membuat masyarakat Bali mengalami proses globalisasi lebih awal dan lebih masif karena interaksi komunal antara masyarakat Bali dengan masyarakat internasional sangat tinggi intensitasnya. Suasana demikian membuat sistem budaya di Bali tidak bisa lepas dari pengaruh globalisasi. Hasil temuan penelitian disertasi Anak Agung Gde Agung menyatakan bahwa sebagian besar kebudayaan Bali sudah menuju tahap erosi. Aspek hubungan manusia dengan alam mengalami erosi sekitar 60\%, hubungan antar manusia telah rusak antara $40-45 \%$, tetapi hubungan manusia dengan Tuhan masih kuat, antara $90-95 \%$. Data ini membuktikan terjadi perubahan nilai dan norma serta kebiasaan hidup. Diantara kelompok masyarakat mulai mempunyai kepentingan yang berbeda dan bahkan sering kali juga bertentangan. Solidaritas mekanis yang semula menjadi daya pengikat tergantikan oleh ikatan solidaritas organis yang lebih menonjolkan ikatan dalam kelompok dan kepentingan kelompok dibandingkan masyarakat secara keseluruhan. Orientasi nilai dalam pergaulan antar sesama mengalami pergeseran dari nilai kebersamaan ke nilai individual, kelompok, dan komersial. Situasi demikian memberi peluang untuk timbulnya persaingan dan konflik integritas masyarakat dan identitas diri bangsa.

SMK kearifan lokal THK kedepan diharapkan menjadi pusat pembudayaan kompetensi dalam membangun sumber daya insani berkarakter budaya belajar (jnana), budaya berkarya (karma), budaya melayani (bhakti), dan bermental sebagai learning person yang mampu menumbuhkan kecerdasan belajar sebagai sentral moralitas untuk mengembangkan kecerdasan emosional-spiritual, kecerdasan sosial-ekologis, kecerdasan intelektual, kecerdasan kinestetis, kecerdasan ekonomika, kecerdasan politik, kecerdasan teknologi, dan kecerdasan seni-budaya berdasarkan nilai-nilai hidup harmonis dan seimbang antara manusia dengan Tuhan Yang Mahaesa (parhyangan), antar sesama manusia (pawongan), antara manusia dengan lingkungan (palemahan).

\section{Misi dan Tujuan Pengembangan SMK Kearifan Lokal THK}

Misi pengembangan SMK kearifan lokal THK adalah: 
1. Menjadikan SMK kearifan lokal THK sebagai solusi masalah menurunnya nilainilai budaya bangsa, integritas, identitas nasional, dan daya saing bangsa Indonesia.

2. Menjadikan SMK kearifan lokal THK sebagai pusat pengembangan budaya belajar, budaya berkarya, budaya melayani orang lain.

3. Menumbuhkan kesadaran THK pada warga sekolah yaitu sadar atman, sadar sarira, sadar prana.

4. Menjadikan SMK kearifan lokal THK sebagai pusat pengembangan karakter kejuruan.

5. Menyelenggarakan pendidikan dan pelatihan pengembangan "guna" atau bakat peserta didik untuk mendapatkan "geginan" atau pekerjaan.

6. Membimbing karir lulusan menjadi pekerja yang profesional sebagai "pragina" agar menjadi insan bermanfaat "manusa meguna".

7. Menyelenggarakan pendidikan kejuruan yang mandiri dalam melakukan peningkatan mutu, relevansi, daya saing, dan efisiensi dengan menerapkan kearifan dan keunggulan lokal THK.

8. Menjadikan SMK sebagai lingkungan tempat membangun kebahagiaan warga sekolah (janahita) dan membangun alam lingkungan sekolah yang lestari (buthahita).

9. Melestarikan ideologi THK sebagai kearifan dan keunggulan lokal dalam memperkokoh nilai-nilai budaya bangsa dan identitas nasional.
Tujuan pengembangan SMK indigenous THK adalah:

1. Mewujudkan SMK sebagai lingkungan belajar THK yang memiliki prahyangan (pura sekolah, pelangkiran kelas/ruang), pawongan (warga sekolah), dan palemahan (areal sekolah dengan seluruh bangunan) sebagai satu kesatuan yang utuh untuk mewujudkan keharmonisan hidup dalam mengembangkan potensi diri masingmasing warga sekolah.

2. Menanamkan nilai-nilai keseimbangan dan keharmonisan hidup dalam diri pribadi masyarakat pendidikan kejuruan melalui pemahaman dan penghayatan atman, prana, dan angga sarira atau badan wadag.

3. Mewujudkan pendidikan yang menghayati keberadaan atman.

4. Mewujudkan pendidikan yang memahami dan mampu mengelola badan wadag sebagai wadah atman anugrah Tuhan yang sempurna perlu dirawat kesehatannya, dikembangkan potensi kelima indrianya (panca indria), potensi kelima alat gerak (panca karmendria), dan potensi panca budindrya.

5. Mewujudkan pendidikan sebagai lingkungan belajar tempat pengembangan kekuatan berpikir/berlogika (idep), kompetensi berkomunikasi (sabda), kompetensi beraktifitas (bayu).

6. Menanamkan nilai-nilai kekuatan prana sabda, bayu, idep untuk memenuhi tuntutan dunia kerja yang mengarah kepada industri berbasis pengetahuan, industri kreatif, soft skill. 
7. Menanamkan nilai-nilai keseimbangan dan keharmonisan hidup antar pribadi masyarakat pendidikan kejuruan melalui pemahaman, penghayatan, pemanfaatan prahyangan, pawongan, dan palemahan.

8. Membangun kesadaran bahwa manusiamanusia yang sehat jasmani, tenang rokhani, dan profesional adalah prana atau kekuatan hidup keluarga, warga banjar, warga desa pakraman masyarakat bali.

9. Membangun SMK sebagai lingkungan untuk mewujudkan lembaga pendidikan menengah kejuruan yang mampu meningkatkan kecerdasan, pengetahuan, kepribadian, ahklak mulia, serta keterampilan untuk hidup mandiri dan mengikuti pendidikan lebih lanjut sesuai dengan kejuruannya secara seimbang dan harmonis sesuai dengan nilai-nilai pokok ideologi THK.

10. Mewujudkan pendidikan kejuruan bervisi kerja pembebasan diri dari hukum punarbhawa, menjadi pekerja yang selalu menambah dan menabung karma baik, berkarakter diri yakin bahwa berbuat baik pasti akan memperoleh hasil yang baik, tidak berputus asa, konsisten, kerja keras, stabil dalam emosi, memiliki spirit dan gairah terus bekerja dengan baik.

\section{KESIMPULAN}

SMK kearifan lokal Tri Hita Karana (THK) adalah sekolah kejuruan yang menerapkan karakter keharmonisan antara warga sekolah dengan sang pencipta Tuhan Yang Mahaesa, keharmonisan antar sesama warga sekolah, dan keharmonisan antara warga sekolah dengan lingkungan sarana dan prasarana sekolah secara keseluruhan dalam melakukan proses vokasinalisasi. Pengembangan SMK kearifan lokal THK mendukung program pendidikan kejuruan menuju pendidikan yang seimbang dan berkelanjutan untuk keharmonisan dan kemajuan sosial bersama, memberi kontribusi pada keharmonisan dan pelestarian lingkungan, pelestarian nilai-nilai budaya, pengukuhan identitas bangsa, bijak dalam menggunakan sumber daya alam, efektif, efisien dalam melakukan perbaikan tenaga kerja terdidik dan terlatih. Pendidikan kejuruan di SMK berbasis kearifan lokal THK dapat mengantisipasi dampak negatif instrusi budaya global, karena THK telah menjadi "taksu" atau modal sosiokultural spiritual dan falsafah hidup masyarakat Bali. Pendidikan kejuruan berbasis kearifan lokal THK perlu dikembangkan secara sistematis untuk meningkatkan keunggulan lokal, kepentingan nasional, keadilan, dan kompetisi antarbangsa dalam peradaban dunia.

\section{UCAPAN TERIMA KASIH}

Ucapan terimakasih disampaikan kepada segenap Pimpinan Program Pascasarjana Universitas Negeri Yogyakarta dan Asosiasi Dosen dan Guru Vokasi Indonesia yang telah memberi fasilitas penerbitan jurnal ADGVI. Semoga tulisan ini dapat memberi inspirasi pengembangan pendidikan vokasi dan kejuruan di Indonesia. 


\section{DAFTAR PUSTAKA}

2009. Peraturan daerah Provinsi Bali nomor 16 Tahun 2009 tentang Rencana Tata Ruang Wilayah Provinsi Bali.

Agastia, IBG. 2007. Mengkritisi Impelemtasi Tri Hita Karana, Warta Hindu Dharma, 491, 4-41.

Cheng, Y.C. 2005. New Paradigm for Reengineering Education, Globalization, Localization and Individualization. Netherland: Springer.

Chinien, C. and Singh, M. 2009. Overview: Adult Education for the Sustainability of Human Kind (2521-2536). Rupert Maclean, David Wilson, Chris Chinien; International Handbook of Education for the Changing World of Work, Bridging Academic and Vocational Learning: Germany: Springer

Chinien, C., Boutin, F., Plane, K. 2009. The Challenge for ESD in TVET: Developing Core Sustainable Develpoment Competencies and Collaborative Social Partnerships for Practice (2553-2570). Rupert Maclean, David Wilson, Chris Chinien; International Handbook of Education for the Changing World of Work, Bridging Academic and Vocational Learning: Germany: Springer

Clarke L. \& Winch C. 2007. Vocational Education International Approaches, development and systems. USA: Routledge.

Depdiknas. 2003. Undang-Undang RI Nomor 20, Tahun 2003, tentang Sistem Pendidikan Nasional.

Depdiknas. 2005. Peraturan Pemerintah RI Nomor 19, Tahun 2005, tentang Standar Nasional Pendidikan.

Depdiknas. 2006. Peraturan Menteri Pendidikan Nasional RI Nomor 22, Tahun 2006, tentang Standar Isi untuk Satuan Pendidikan Dasar dan Menengah.

Depdiknas. 2006. Peraturan Menteri Pendidikan Nasional RI Nomor 23, Tahun 2006, tentang Standar Kompetensi Lulusan untuk Satuan Pendidikan Dasar dan Menengah.
Hampden, G., Thompson, Guzman, L., and Lippman, L. 2008. Cultural Capital: What Does It Offer Students? A Cross-National Analysis (155-180). In Zajda, J., Biraimah, K., Gaudell, W (Eds.), Education and Social Inequality ing the Global Culture (pp. 155-180). Melbourne: Springer Science + Business Media B.V.

Coessens,K. and Bendegem, J.P.V.2008. Cultural Capital as Educational Capital, The Need For a Reflection on the Educationalisation of Cultural Taste, Paul Smeyers · Marc Depaepe, Educational Research: the Educationalization of Social Problems. London: Springer Science+Business Media B.V.

Oketch, M. O. 2009. To Vocationalize or Not to Vocationalize? Perspectives on Current Trends and Issues on TVET in Africa. In R. Maclean, D. Wilson, \& C. Chinien (Eds.), International Handbook of Education for the Changing World of Work, Bridging Academic and Vocational Learning (pp. 531-546). Germany: Springer.

Oketch, M. O., Green, A., \& Preston, J. 2009. Trends an Issues in TVET across the Globe. In R. Maclean, D. Wilson, \& C. Chinien (Eds.), International Handbook of Education for the Changing World of Work, Bridging Academic and Vocational Learning (pp. 2081-2094). Germany: Springer.

Pavlova M. 2009. The Vocationalization of Secondary Education: The Relationships between Vocational and Technology Education. In R. Maclean, D. Wilson, \& C. Chinien (Eds.), International Handbook of Education for the Changing World of Work, Bridging Academic and Vocational Learning (pp. 1805-1822). Germany: Springer.

Rojewski. J.W. 2009. A Conceptual Framework for Technical and Vocational Education and Training. In R. Maclean, D. Wilson, \& C. Chinien (Eds.), International Handbook of Education for the Changing World of Work, Bridging Academic and Vocational Learning (pp. 19-40). Germany: Springer. 
Singh, M. 2009. Social and Cultural Aspects of Informal Sector Learning: Meeting the Goals of EFA. In R. Maclean, D. Wilson, \& C. Chinien (Eds.), International Handbook of Education for the Changing World of Work, Bridging Academic and Vocational Learning (pp. 349-364). Germany: Springer.

Slamet,P.H. 2008. Desentralisasi Pendidikan Indonesia. Jakarta: Departemen Pendidikan Nasional

Thompson, John F. 1973. Foundation of Vocational Education Social and Philosophical Concepts. New Jersey: Prentice-Hall.

Tilaar, H.A.R. 1999. Pendidikan Kebudayaan, dan Masyarakat Madani Indonesia. Bandung: PT. Remaja Rosdakarya.

Tilaar, H.A.R. 2002. Perubahan Sosial dan Pendidikan, Pengantar Pedagogik Transformatif untuk Indonesia. Jakarta: PT. Gramedia.

Titib, I Made. (2007). Aktualisasi Ajaran Tri Hita karana dalam Konsep Desa Adat di Bali, Makalah Dharma Wacana dengan tema Hubungan Tri Hita Karana, dilaksanakan oleh Keluarga Besar Arya Tegeh Kori, Banjar Pragae Desa Mengwi Gede, Kecamatan Mengwi, Kabupaten Badung.

Wastika, D.N. 2005. Penerapan Konsep Tri Hita Karana Dalam Perencanaan Perumahan di Bali. Jurnal Permukiman Natah Vol. 3 No. 2, 62 - 105.
Wagner, T. 2008. The Global Achievement Gap. New York: Basic Books.

Wiana, IK. 29 November 2003. Kewajiban Utama Desa Pakraman Menegakkan Tattwa. Diunduh pada tanggal 12 Oktober 2010, dari http://www.iloveblue.com/bali_gaul_funk y/artikel_bali/category/KETUT\%20WIA NA/10/13.htm

Wiana, IK. 20 Juli 2009. Membenahi Motivasi Kerja. Diunduh pada tanggal 2 Juni 2010, dari

http://www.iloveblue.com/bali_gaul_funk y/ artikel_bali/detail/2820.htm

Wiana, IK. 8 Juni 2009. Tantangan SDM Hindu kedepan. Diunduh pada tanggal 2 Jui 2010, dari http://www.iloveblue.com/bali_gaul_funk y/artikel_bali/detail/2820.htm

Wiana, IK. 8 Juni 2009. Kegiatan Beragama Hindu Membangun SDM Bermutu. Diunduh pada tanggal 2 Juni 2010, dari http://www.iloveblue.com/ baligaulfunky/ rtikel_bali/detail/2820.htm

Wiana, IK. 6 April 2009. Dosa kalau Pendidikan tanpa Karakter. Diunduh pada tanggal 2 Juni 2010, dari http://www.iloveblue.com/ baligaulfunky/ rtikel_bali/detail/2820.htm.

Zajda, J., Biraimah, K., Gaudelli, W. 2008. Cultural Capital: What Does It Offer Students? A Cross-National Analysis. Education and Social Inequality in the Global Culture Melbourne: Springer Science + Business Media B.V. 